\title{
EXPERIMENTAL ASSESSMENT OF THE MELISS SIMULATION MODEL ACCURACY OF THE DIRECT SOLAR IRRADIANCE IN BRASOV, ROMANIA
}

\author{
Camelia Liliana Moldovan ${ }^{1 *}$, Radu Paltanea ${ }^{1}$, Ion Visa ${ }^{2}$ \\ ${ }^{I}$ Faculty of Mathematics and Informatics, Transilvania University of Brasov, 29 Eroilor Bd., Brasov, Romania \\ ${ }^{2}$ Renewable Energy Systems and Recycling (RESREC) Research Centre, R\&D Institute of the Transilvania \\ University of Brasov, 29 Eroilor Bd., Brasov, Romania
}

\begin{tabular}{|l|l|}
\hline \multicolumn{1}{|c|}{ Article Info } & \multicolumn{1}{c|}{ Abstract } \\
\hline Received: 15.03.2018 & \multicolumn{1}{|c|}{ The solar irradiance is the main input parameter when designing solar } \\
Accepted: 15.06.2018 & $\begin{array}{l}\text { energy conversion systems. A poor accuracy of the solar irradiance simulation } \\
\text { models negatively affect the output energy and the durability of the solar energy } \\
\text { conversion system. In the paper, the measured values of the direct solar irradiance } \\
\text { in the entire month of July 2016 are analysed and, based on the daily received } \\
\text { irradiance, clear sky } \\
\text { dimulation solar energy and the variability of the direct solar irradiance, the days are } \\
\text { experimental assessment } \\
\text { classified in four categories: clear sky days, partially clear sky days, partially } \\
\text { cloudy days and cloudy days. Based on this classification, only four clear sky days } \\
\text { were identified in July 2016. The same procedure was applied for the months of } \\
\text { July 2013, 2014 and 2015 resulting 13 clear sky days in the entire monitoring } \\
\text { period of four years (2013-2016). The measured values of the direct solar } \\
\text { irradiance in these 13 selected clear sky days are comparatively analysed against } \\
\text { the direct solar irradiance simulated with Meliss clear sky model. Further on, a } \\
\text { statistical analysis is performed for the time interval 8:00-16:00 to evaluate } \\
\text { absolute, relative and root mean square errors between the measured and simulated } \\
\text { values. The results show that the simulation model overestimates, in eleven out of } \\
\text { the thirteen clear sky days, the solar direct irradiance in the central part of the day. } \\
\text { The measurements were performed in the Renewable Energy Systems and } \\
\text { Recycling (RESREC) Research Centre located in the R\&D Institute of the } \\
\text { Transilvania University of Brasov, Romania. }\end{array}$ \\
\hline
\end{tabular}

\section{Introduction}

In the design process of the renewable energy systems converting solar energy in thermal and/or electrical energy, the accuracy of input data is of great importance. Both peak values of solar irradiance (clear sky conditions) and daily/monthly received solar energy are considered. Overrating of the received solar irradiance/energy conduct to undersized systems, lower solar fraction and higher rates of fossil fuels consumptions and related greenhouse gases emissions. Even the underestimations are detrimental, leading to oversized systems 
with higher (unjustified) investments costs and worsening the durability of the system component generated by more frequent overheating throughout stagnation periods in the case of solar thermal systems.

Usually, clear sky models [1], sunshine-based models [2, 3], cloud-based models [4], temperature-based models [5] and other meteorological parameters-based models [6] are used to estimate the instantaneous solar irradiance and the daily/monthly solar energy received from the Sun.

Comparisons between experimental and simulated solar irradiance were reported all over the world. Ineichen performed such a comparison between measured data in 16 location situated in Europe (Germany, Switzerland, Portugal) and USA against 8 clear sky models, showing that the turbidity factor has the highest influence on model accuracy [7]. Engerer and Mills obtained similar results, validating nine clear sky models based on measured data from 20 sites in Australia [8]. In Romania, Isvoranu and Badescu concluded that the computed global solar irradiance based on MM5 model of Dudhia fits, with errors between $3.84 \%$ and $11.87 \%$, the experimental data from five National Meteorological Administration stations (Timisoara, Cluj, Iasi, Galati and Craiova) [9]. Mares, Vizman and Paulescu compared measured values recorded on the Solar Platform of the West University of Timisoara [10] with a model based on the sunshine number defined by Badescu as a time dependent random binary variable [11], and proposed dynamic correction for the average atmospheric transmittance to improve the accuracy of the clear sky model.

In the paper, the measured values of the direct solar irradiance in the entire month of July 2016 are analysed and, based on the daily received direct solar energy and the variability of the direct solar irradiance, the days are classified in four categories: clear sky days, partially clear sky days, partially cloudy days and cloudy days. Based on this classification, only four clear sky days were identified in July 2016. The same procedure was applied for the months of July 2013, 2014 and 2015 resulting 13 clear sky days in the entire monitoring period of four years (2013-2016). The measured values of the direct solar irradiance in these 13 selected clear sky days are comparatively analysed against the direct solar irradiance simulated with Meliss clear sky model [1]. Further on, a statistical analysis is performed for the time interval 8:00-16:00 to evaluate absolute, relative and root mean square errors between the measured and simulated values. The results show that the simulation model overestimates, in eleven out of the thirteen clear sky days, the solar direct irradiance in the central part of the day. The measurements were performed in the Renewable Energy Systems 
and Recycling (RESREC) Research Centre located in the R\&D Institute of the Transilvania University of Brasov, Romania.

\section{Method}

The direct solar irradiance have been measured since 2013 using a First Class CHP1 pyrheliometer (daily uncertainty $< \pm 1 \%$ ) installed on a Solys2 Sun Tracker (pointing accuracy $<0.1^{\circ}$ ), both from Kipp\&Zonen. Along with the direct solar irradiance, diffuse and global solar irradiance in the horizontal plane have been also measured using Secondary Standard CMP22 pyranometers (daily uncertainty $<0.5 \%$ ) with and respectively without shading ball device. The described instruments are installed on the rooftop of the Laboratory building of the Renewable Energy Systems and Recycling (RESREC) Research Centre located in the R\&D Institute of the Transilvania University of Brasov, Romania.

The measurements are done every 15 seconds, thus 4 measurements per minute, out of which four samples are stored in a database each minute: minimum, average, maximum and standard deviation. In this study, maximum value of the direct solar irradiance $\left(B_{\text {exp }}, i\right)$ was considered for each minute " $i$ " to avoid accidental shadings of the instruments (e.g. by birds flying over the instruments). The local standard time is converted to apparent solar time using the well-known equation of time and longitude correction [12]. Additionally, for each minute " $i$ ", the mean value of the direct solar irradiance $\left(B_{\operatorname{exp~}, \mathrm{i}}\right)$ is calculated averaging the values measured in that minute $\left(\mathrm{B}_{\mathrm{exp}, \mathrm{i}}\right)$ in all the " $\mathrm{k}$ " clear sky days during the monitoring period with:

$$
B_{\exp m, i}=\frac{\sum_{j=1}^{k} B_{\exp , i}^{j}}{k},\left[\mathrm{~W} / \mathrm{m}^{2}\right]
$$

Based on these values, the experimental $\left(E_{B \exp , i}\right)$ and mean experimental $\left(E_{B \operatorname{exp~m}, i}\right)$ received direct solar energy are further approximated over a period of time between $t_{1}$ and $t_{2}$ (apparent solar time), considering the direct solar irradiance $\left(\mathrm{B}_{\mathrm{exp}, \mathrm{i}}\right)$ constant over a time interval $\tau$ of one minute between two measurements, with:

$$
\begin{aligned}
& E_{B_{\text {exp }}}=\frac{1}{60} \sum_{i=t_{1}}^{t_{2}} B_{\exp , i} \tau,\left[\mathrm{Wh} / \mathrm{m}^{2}\right] \\
& E_{B_{\exp \varpi m}}=\frac{1}{60} \sum_{i=t_{1}}^{t_{2}} B_{\exp m, i} \tau,\left[\mathrm{Wh} / \mathrm{m}^{2}\right]
\end{aligned}
$$


For the month of July, the time interval $\left[t_{1}, t_{2}\right]$ was firstly considered as between 04:00 -20:00 to evaluate the daily available direct solar energy needed to classify the days. Further on, for the case of fixed, south oriented solar convertors, the interval 08:00 - 16:00 is of interest, due to the solar azimuthal angle which is $95.22^{\circ}$ at 7:00 and $84.44^{\circ}$ at 8:00 for Brasov. The solar azimuthal angle continuously decreases, reaching $0^{\circ}$ at noon and symmetrical but negative values in the afternoon (e.g. $-84.44^{\circ}$ at $16: 00$ and $-95.22^{\circ}$ at 17:00). The variation of solar azimuthal and elevation angles combined with fixed azimuthal and elevation angles of the solar convertors $\left(0^{\circ}\right.$ and $38^{\circ}$ respectively, corresponding to South oriented solar convertors optimally tilted for Brasov) generates high incidence angles before 8:00 and after 16:00 (e.g. 78.5 at 7:00 and 17:00). These high incidence angles correspond to lower values for the received direct solar irradiance on the solar convector surface than in the 08:00-16:00 time interval.

Further on, Meliss clear sky model [1] is used to simulate each minute " $i$ " the direct solar irradiance at ground level $\left(\mathrm{B}_{\mathrm{i}}\right)$ for Brasov, $45.67^{\circ} \mathrm{N}$ latitude and $25.55^{\circ} \mathrm{E}$ longitude, with:

$$
B_{i}=B_{0} \cdot e^{\left(\frac{-T_{R}}{0.9+9.4 \sin \alpha_{i}}\right)},\left[\mathrm{W} / \mathrm{m}^{2}\right]
$$

The solar irradiance at the upper limit of the Earth atmosphere $\left(\mathrm{B}_{0}\right)$ depends on the distance between the Earth and the Sun, ranging between a $1413 \mathrm{~W} / \mathrm{m}^{2}$ in $3^{\text {rd }}$ of January corresponding to the smallest Earth-Sun distance and $1321 \mathrm{~W} / \mathrm{m}^{2}$ in $3^{\text {rd }}$ of July corresponding to the farthest Earth-Sun position, values calculated using well-known equations [12]. The turbidity factor $\left(T_{R}\right)$ is affected by the local conditions of the atmosphere with monthly values between 2.8 and 3.2 for Brasov region $[13,14]$. The solar elevation angle $(\alpha)$ varies daily between zero (at sunrise and sunset) and a maximum value at noon; this maximum value is season dependent: highest/smallest values are reached at summer/winter solstice [15].

The received direct solar energy $\left(\mathrm{E}_{\mathrm{B}}\right)$ is further approximated with:

$$
E_{B}=\frac{1}{60} \sum_{i=t_{1}}^{t_{2}} B_{i} \cdot \tau,\left[\mathrm{Wh} / \mathrm{m}^{2}\right]
$$

The absolute error is calculated as the difference between experimental $\left(\mathrm{B}_{\text {exp, }}\right)$ and simulated $\left(\mathrm{B}_{\mathrm{i}}\right)$ direct solar irradiance, with: 


$$
\varepsilon_{B, i}=B_{\exp , i}-B_{i},\left[\mathrm{~W} / \mathrm{m}^{2}\right]
$$

This absolute error, measured in $\left[\mathrm{W} / \mathrm{m}^{2}\right]$, may be both positive and negative during a day.

The mean absolute error is calculated as the difference between mean experimental $\left(\mathrm{B}_{\operatorname{exp~} \mathrm{m}, \mathrm{i}}\right)$ and mean simulated $\left(\mathrm{B}_{\mathrm{m}, \mathrm{i}}\right)$ direct solar irradiance, with:

$$
\varepsilon_{B m, i}=B_{\exp m, i}-B_{m, i},\left[\mathrm{~W} / \mathrm{m}^{2}\right]
$$

The relative error between experimental $\left(B_{\exp }, i\right)$ and simulated $\left(B_{i}\right)$ direct solar irradiance is calculated with:

$$
\varepsilon_{r B, i}=\frac{\varepsilon_{B, i}}{B_{\exp , i}} \cdot 100,[\%]
$$

The mean relative error between mean experimental $\left(B_{\exp m, i}\right)$ and mean simulated $\left(\mathrm{B}_{\mathrm{m}, \mathrm{i}}\right)$ is calculated with:

$$
\varepsilon_{r B m, i}=\frac{\varepsilon_{B m, i}}{B_{\exp [m, i}} \cdot 100,[\%]
$$

The absolute root mean square error between experimental $\left(B_{\text {exp, }}\right)$ and simulated $\left(B_{i}\right)$ direct solar irradiance for the " $\mathrm{n}$ " samples over the considered time interval is calculated with:

$$
\mathrm{RMSE}=\sqrt{\frac{\sum_{i=1}^{n}\left(\boldsymbol{B}_{\text {exp }, i}-\boldsymbol{B}_{i}\right)^{2}}{n}},\left[\mathrm{~W} / \mathrm{m}^{2}\right]
$$

The relative root mean square error between experimental $\left(\mathrm{B}_{\exp , \mathrm{i}}\right)$ and simulated $\left(\mathrm{B}_{\mathrm{i}}\right)$ direct solar irradiance for the " $n$ " samples over the considered time interval is calculated with:

$$
\mathrm{rRMSE}=\sqrt{\frac{\sum_{i=1}^{n}\left(\varepsilon_{r B, i}\right)^{2}}{n}},[\%]
$$

Similarly, the absolute and relative errors between the experimental $\left(E_{B \exp }\right)$ and simulated $\left(E_{B}\right)$, respectively between mean experimental $\left(E_{B e x p ~ m}\right)$ and mean simulated $\left(E_{B} m\right)$ received direct solar energy are calculated with: 


$$
\begin{aligned}
& \varepsilon_{E}=E_{B_{\exp }}-E_{B},\left[\mathrm{Wh} / \mathrm{m}^{2}\right] \\
& \varepsilon_{r_{E}}=\frac{\varepsilon_{E}}{E_{B \exp }} \cdot 100,[\%] \\
& \varepsilon_{E m}=E_{B \exp m}-E_{B m},\left[\mathrm{Wh} / \mathrm{m}^{2}\right] \\
& \varepsilon_{r_{E m}}=\frac{\varepsilon_{E m}}{E_{B_{\exp m}}} \cdot 100,[\%]
\end{aligned}
$$

\section{Results and Discussions}

For 2016, the daily available direct solar energy is evaluated based on eq. (2) and the results are arranged in decreasing order as plotted in Figure 1. Analysing the variability of the direct solar irradiance during each day, four types of days are identified: clear sky days, partially clear sky days, partially cloudy days and cloudy days with thresholds highlighted with dotted lines in Figure 1. Thus, only four days were identified as clear sky days in 2016.

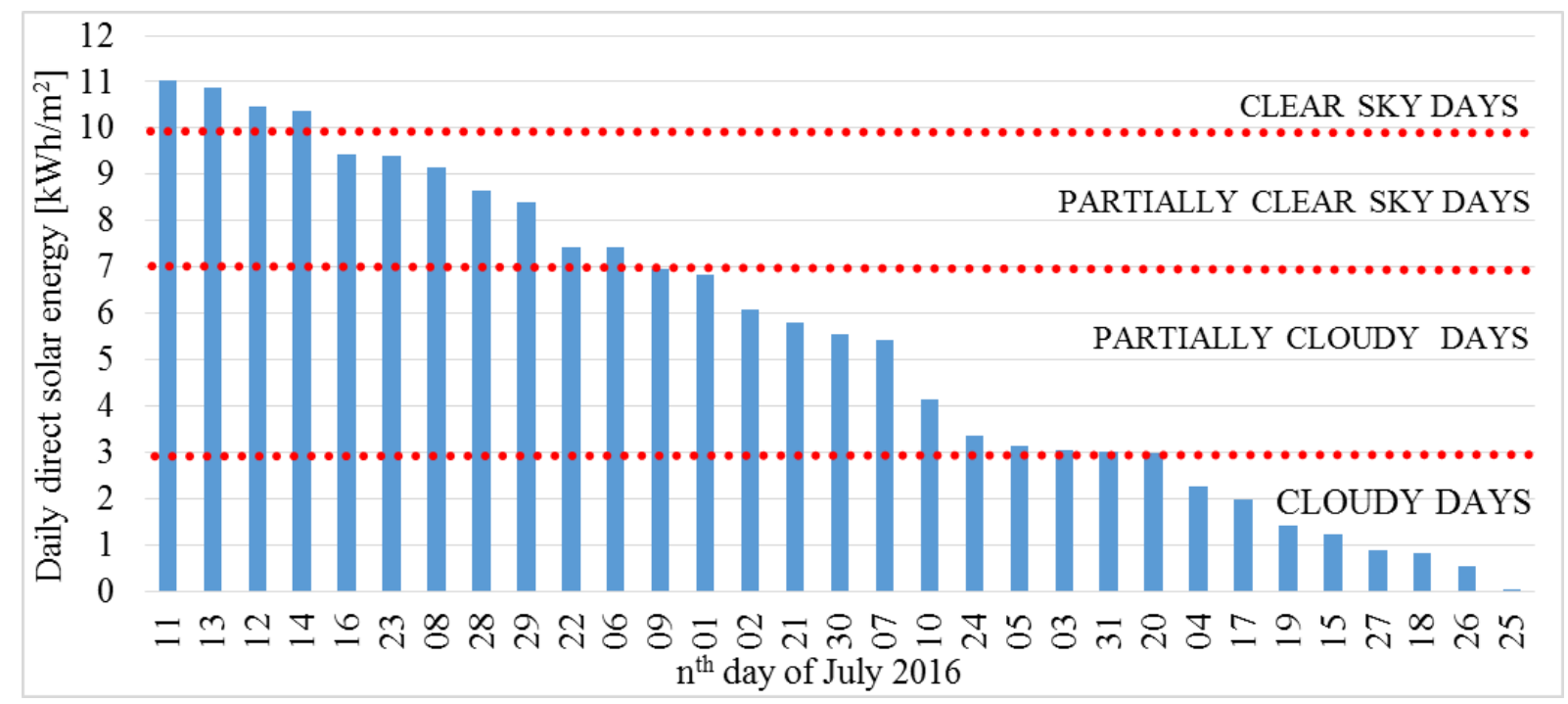

Fig. 1 The distribution of the daily direct solar energy in July 2016

For the same type of days, the mean value of the experimental direct solar irradiance $\left(B_{\text {exp_m }}\right)$ is calculated with eq. (1), resulting four curves: $B_{\text {exp_m1 }}$ for the four clear sky days, $\mathrm{B}_{\text {exp_m2 }}$ for the seven partially clear sky days, $\mathrm{B}_{\text {exp_m3 }}$ for the twelve partially cloudy days and $\mathrm{B}_{\text {exp_m4 }}$ for the eight cloudy days. These curves are plotted in Figure 2 along with the simulated direct solar irradiance (B) obtained for $15^{\text {th }}$ of July 2016. 


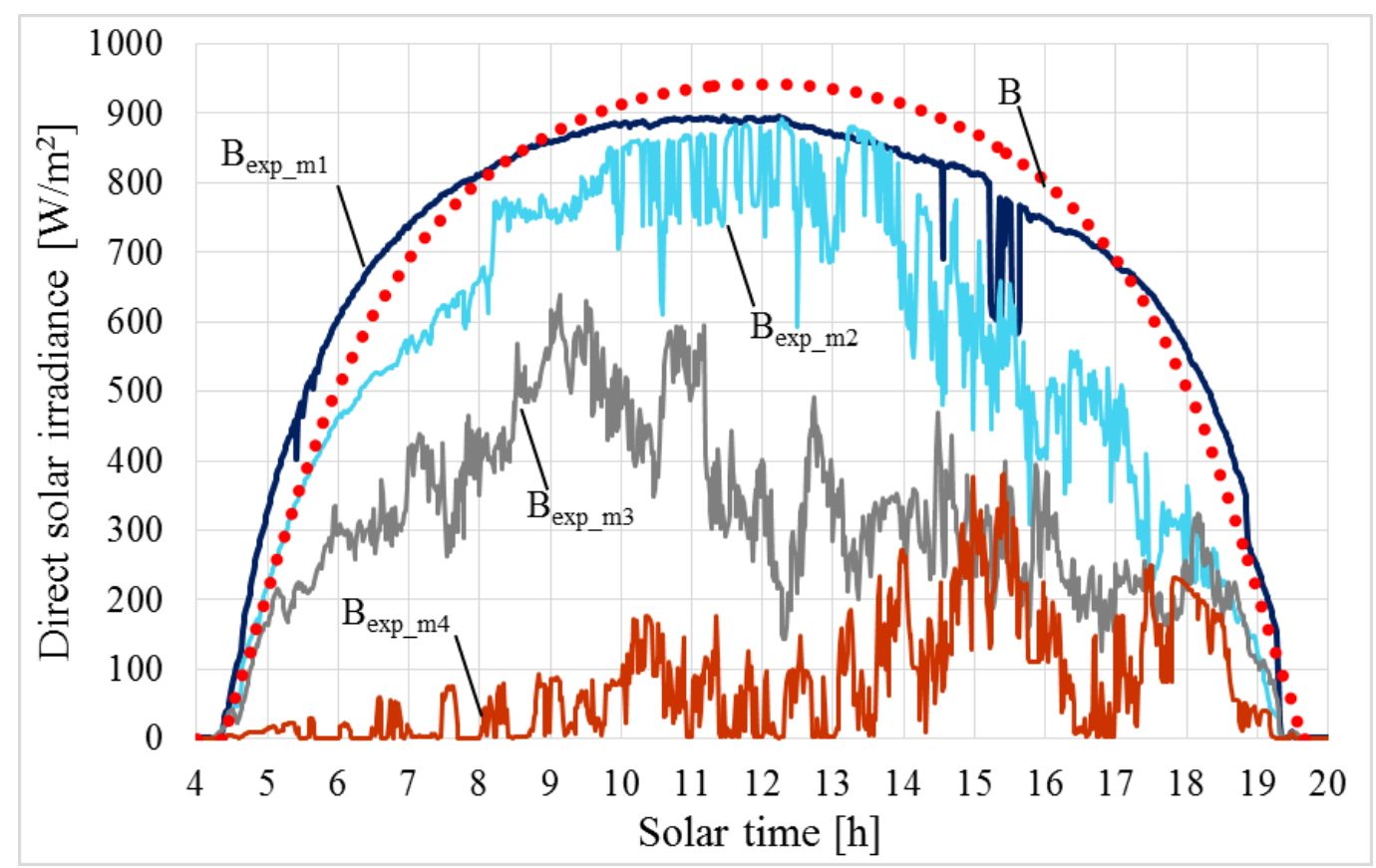

Fig. 2 Mean experimental and simulated direct solar irradiance daily variation in July 2016

In the case of the clear sky days, the mean experimental direct solar irradiance $\left(\mathrm{B}_{\text {exp_m1 }}\right)$ is underestimated by the model in the morning (04:30-08:30) and in the evening (17:0019:30) indicating that the turbidity of the atmosphere was lower than considered $\left(T_{R}=3.2\right)$. In the central part of the day (08:30-17:00), the model overestimates the direct solar irradiance pointing a higher turbidity. As expected, in the case of the other types of days $\left(\mathrm{B}_{\text {exp_m2, }}\right.$ $\mathrm{B}_{\text {exp_m3}}$, and $\left.\mathrm{B}_{\text {exp_m4}}\right)$, the model overestimates the direct solar irradiance since these days are not clear sky days for which the model was proposed. Absolute and relative root mean square errors were calculated on the time interval 08:00-16:00 for each type of days in July 2016 (Table 1). The very high errors obtained in the case of partially cloudy and cloudy days are caused by the lower experimental direct solar irradiance than simulated ones by clear sky Meliss model.

Table 1 Absolute and relative root mean square errors for the 08:00-16:00 time interval

\begin{tabular}{|l|c|c|c|c|}
\hline Error & $\mathrm{B}_{\text {exp_m1 }}$ & $\mathrm{B}_{\text {exp_m2 }}$ & $\mathrm{B}_{\text {exp_m3 }}$ & $\mathrm{B}_{\text {exp_m4 }}$ \\
\hline RMSE $\left[\mathrm{W} / \mathrm{m}^{2}\right]$ & 65.80 & 184.36 & 528.95 & 810.85 \\
\hline rRMSE $[\%]$ & 9.23 & 32.78 & 179.44 & 15923.05 \\
\hline
\end{tabular}

The procedure of identifying the clear sky days was repeated for the months of July in 2013, 2014 and 2015 for which the number of clear sky days is presented in Table 2. 
Table 2 The number of clear sky in July days in monitoring interval (2013 - 2016)

\begin{tabular}{|l|c|c|c|c|c|}
\hline Year & 2013 & 2014 & 2015 & 2016 & $2013-2016$ \\
\hline No. of clear sky days in July & 2 & 3 & 4 & 4 & 13 \\
\hline
\end{tabular}

For each clear sky day, Meliss model was applied to calculate the direct solar irradiance (B) comparatively presented with experimental direct solar irradiance $\left(\mathrm{B}_{\exp }\right)$ in Fig. 3 along with the mean values of all the experimental values $\left(B_{\operatorname{exp~m}}\right)$. Excepting $17^{\text {th }}$ and $22^{\text {nd }}$ of July 2015, the Meliss model generated overestimations of the direct solar irradiance in the 8:00 16:00 interval. The overestimations have a maximum absolute error of $-210.45 \mathrm{~W} / \mathrm{m}^{2}$ (07.07.2014) between experimental $\left(B_{\exp }\right)$ and simulated $(B)$ values, and $-140.86 \mathrm{~W} / \mathrm{m}^{2}$ between mean experimental $\left(B_{\operatorname{exp~}}\right)$ and simulated $\left(B_{m}\right)$ values. Thus, one can say that the use of the mean experimental direct solar irradiance $\left(B_{\operatorname{exp~} m}\right)$ can improve the accuracy of the simulation. The time period between 8:00 and 16:00 was chosen because in the mornings and evenings there are several moments when direct solar irradiance dropped and in these short periods of time the clear sky conditions were not met. Even in this interval, in 12.07.2016 few drops occurred in solar irradiance, these values were not considered in the error analysis.

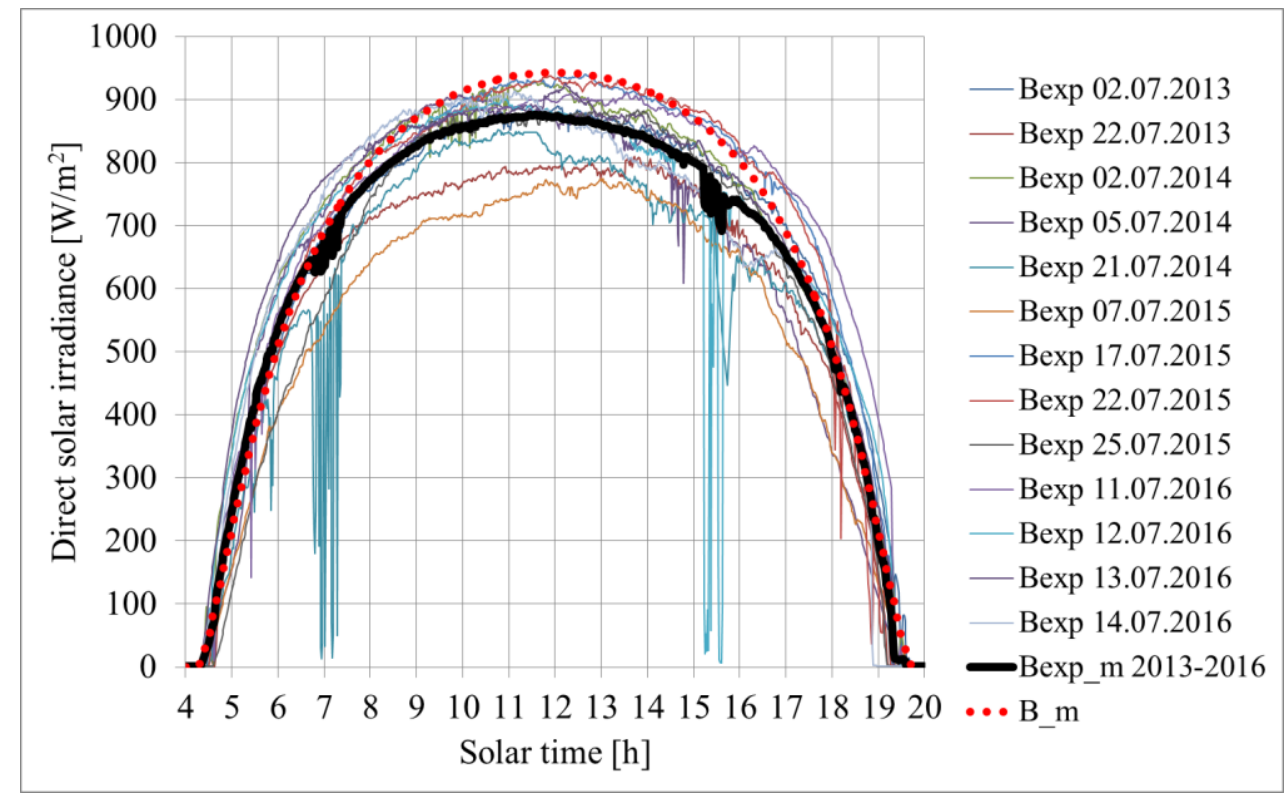

Fig. 3 Simulated and experimental direct solar irradiance daily variation in July 2013-2016

Further on, a clear sky day was selected for each year (Fig. 4) and discussed for the 08:00-16:00 time interval. Among these, only on $17^{\text {th }}$ of July 2015 the simulation was validated by the experimental values (Fig.4a), the maximum absolute error was $-42.45 \mathrm{~W} / \mathrm{m}^{2}$, followed by days like $2^{\text {nd }}$ of July 2014 (Fig.4b) and $12^{\text {th }}$ of July 2016 (Fig.4c) when the 
maximum absolute errors were $-98.14 \mathrm{~W} / \mathrm{m}^{2}$ and $-122.49 \mathrm{~W} / \mathrm{m}^{2}$ respectively. The worst day was $22^{\text {nd }}$ of July 2013 (Fig.4d), when the maximum absolute error was $-163.40 \mathrm{~W} / \mathrm{m}^{2}$.

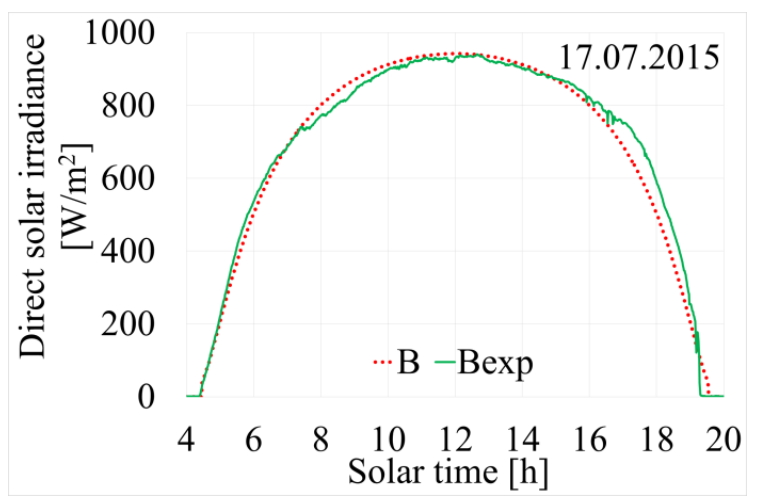

a)

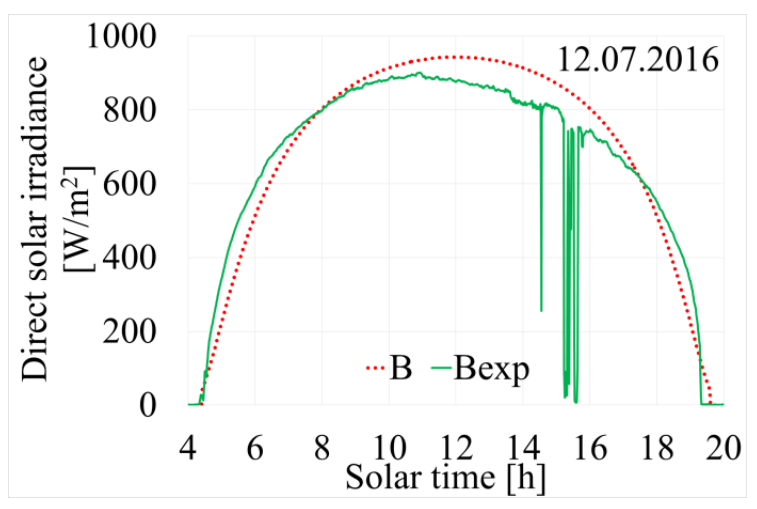

c)

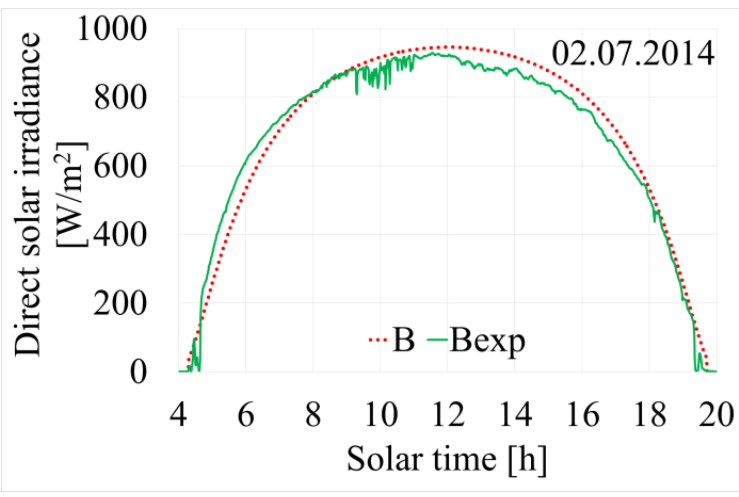

b)

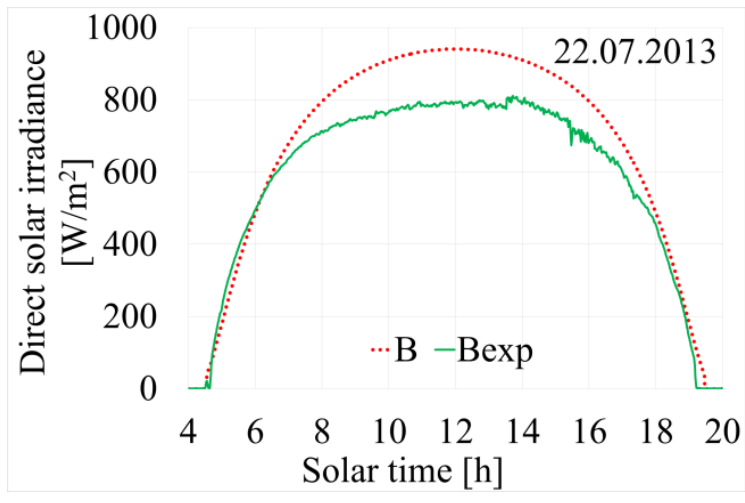

d)

Fig. 4 Simulated and experimental direct solar irradiance in the four selected clear sky days

The maximum absolute and relative errors between experimental $\left(\mathrm{B}_{\exp , \mathrm{i}}\right)$ and simulated $\left(\mathrm{B}_{\mathrm{i}}\right)$, and between mean experimental $\left(\mathrm{B}_{\exp \mathrm{m}, \mathrm{i}}\right)$ and mean simulated $\left(\mathrm{B}_{\mathrm{m}, \mathrm{i}}\right)$ direct solar irradiance in 8:00-16:00 interval for the 13 clear sky days in July 2013-2016 are presented in the Table 3 along with the absolute and relative root mean squared errors $(n=480)$.

The absolute root mean square errors vary between $17.36 \mathrm{~W} / \mathrm{m}^{2}$ and $179.66 \mathrm{~W} / \mathrm{m}^{2}$, corresponding to relative root mean square errors of $1.99 \%$ and $24.88 \%$. Acceptable rRMSE $(<5 \%)$ were obtained only for four days, rRMSE between $5 \%$ and $10 \%$ were found in the case of another five days, and higher than $10 \%$ for the rest of four days showing that the model does not provide accurate simulations for the 08:00-16:00 time interval. To evaluate if the model under- or overestimates the direct solar irradiance, absolute and relative errors were calculated. The maximum relative errors have negative values varying between $-29.42 \%$ 
and $-3.75 \%$. This highlights once again the overestimation effect of the Meliss model. The mean relative error between mean experimental $\left(B_{\operatorname{exp~m,i}}\right)$ and mean simulated $\left(B_{m, i}\right)$ direct solar irradiance has a maximum value of $-20.49 \%$, showing an important deviation of the simulation values in the 08:00-16:00 time interval.

Table 3. Errors between experimental and simulated direct solar irradiance (8:00-16:00)

\begin{tabular}{|c|c|c|c|c|c|c|}
\hline Day & $\begin{array}{c}\max \varepsilon_{\boldsymbol{B}, \boldsymbol{i}} \\
{\left[\mathrm{W} / \mathrm{m}^{2}\right]}\end{array}$ & $\begin{array}{c}\max \varepsilon_{\boldsymbol{B} \boldsymbol{m}, \boldsymbol{i}} \\
{\left[\mathrm{W} / \mathrm{m}^{2}\right]}\end{array}$ & $\begin{array}{c}\max \varepsilon_{\boldsymbol{r} B, \boldsymbol{i}} \\
{[\%]}\end{array}$ & $\begin{array}{c}\max \boldsymbol{\varepsilon}_{\boldsymbol{r} \boldsymbol{B} \boldsymbol{m}, \boldsymbol{i}} \\
{[\%]}\end{array}$ & $\begin{array}{l}\text { RMSE } \\
{\left[\mathrm{W} / \mathrm{m}^{2}\right]}\end{array}$ & $\begin{array}{c}\text { rRMSE } \\
{[\%]}\end{array}$ \\
\hline 02.07 .2013 & -97.52 & \multirow{13}{*}{-140.86} & -11.80 & \multirow{13}{*}{-20.35} & 62.49 & 7.40 \\
\hline 22.07 .2013 & -163.40 & & -24.22 & & 131.18 & 17.04 \\
\hline 02.07 .2014 & -98.14 & & -11.92 & & 38.10 & 4.45 \\
\hline 05.07 .2014 & -168.57 & & -25.58 & & 75.93 & 9.80 \\
\hline 21.07 .2014 & -188.13 & & -26.70 & & 110.13 & 14.29 \\
\hline 07.07 .2015 & -210.45 & & -29.42 & & 179.66 & 24.88 \\
\hline 17.07 .2015 & -42.45 & & -5.37 & & 18.38 & 2.19 \\
\hline 22.07 .2015 & -31.88 & & -3.75 & & 17.36 & 1.99 \\
\hline 25.07 .2015 & -79.30 & & -9.23 & & 52.24 & 6.17 \\
\hline 11.07 .2016 & -51.41 & & -5.79 & & 32.39 & 3.68 \\
\hline 12.07 .2016 & -122.49 & & -17.52 & & 60.35 & 7.30 \\
\hline 13.07 .2016 & -70.80 & & -8.47 & & 44.64 & 5.20 \\
\hline 14.07 .2016 & -143.93 & & -21.54 & & 79.96 & 10.31 \\
\hline
\end{tabular}

The daily experimental, mean experimental and simulated direct solar energy were calculated, with eq. (2), (3) and (5) and the results obtained for the time interval 8:00-16:00 are comparatively presented in Table 4 , along with the associated errors calculated based on eq. (12-15).

The experimentally evaluated direct solar energy over the clear sky days in July 20132016 vary between $5.80 \mathrm{kWh} / \mathrm{m}^{2}$ and $7.14 \mathrm{kWh} / \mathrm{m}^{2}$, over the time interval 08:00-16:00. When comparing with the direct solar energy obtained based on simulations, the absolute errors ranges between $-1.43 \mathrm{kWh} / \mathrm{m}^{2}$ and $-0.04 \mathrm{kWh} / \mathrm{m}^{2}$ and the relative errors reach values as high as $-24.73 \%$. These high relative errors are not acceptable in the design process. One solution to compensate this large error generated through simulations is to use the mean values of the experimentally obtained direct solar energy. The absolute error between mean experimental 
and mean simulated direct solar energy is $-0.53 \mathrm{kWh} / \mathrm{m}^{2}$ corresponding to a relative error of $-7.95 \%$ which is still significant especially when large solar converting systems are designed.

Table 4. Simulated and experimental direct solar energy and associated errors (8:00-16:00)

\begin{tabular}{|c|c|c|c|c|c|c|c|}
\hline Day & $\begin{array}{c}\boldsymbol{E}_{\boldsymbol{B}} \\
{\left[\mathrm{KWh} / \mathrm{m}^{2}\right]}\end{array}$ & $\begin{array}{c}\boldsymbol{E}_{\boldsymbol{B}_{\text {exp }}} \\
{\left[\mathrm{KWh} / \mathrm{m}^{2}\right]}\end{array}$ & $\begin{array}{c}\boldsymbol{E}_{\boldsymbol{B}_{\text {exp } \boldsymbol{m}}} \\
{\left[\mathrm{KWh} / \mathrm{m}^{2}\right]}\end{array}$ & $\begin{array}{c}\varepsilon_{\boldsymbol{E}} \\
{\left[\mathrm{KWh} / \mathrm{m}^{2}\right]}\end{array}$ & $\begin{array}{c}\boldsymbol{\varepsilon}_{\boldsymbol{E} \boldsymbol{m}} \\
{\left[\mathrm{KWh} / \mathrm{m}^{2}\right]}\end{array}$ & $\begin{array}{l}\boldsymbol{\varepsilon}_{r_{E}} \\
{[\%]}\end{array}$ & $\begin{array}{l}\varepsilon_{r_{E m}} \\
{[\%]}\end{array}$ \\
\hline 02.07 .2013 & 7.25 & 6.75 & \multirow{13}{*}{6.68} & -0.50 & \multirow{13}{*}{-0.53} & -7.34 & \multirow{13}{*}{-7.95} \\
\hline 22.07 .2013 & 7.19 & 6.15 & & -1.04 & & -16.91 & \\
\hline 02.07 .2014 & 7.25 & 6.99 & & -0.26 & & -3.76 & \\
\hline 05.07 .2014 & 7.24 & 6.75 & & -0.50 & & -7.36 & \\
\hline 21.07 .2014 & 7.19 & 6.21 & & -0.98 & & -15.70 & \\
\hline 07.07 .2015 & 7.24 & 5.80 & & -1.43 & & -24.73 & \\
\hline 17.07 .2015 & 7.21 & 7.11 & & -0.09 & & -1.31 & \\
\hline 22.07 .2015 & 7.19 & 7.14 & & -0.04 & & -0.61 & \\
\hline 25.07 .2015 & 7.17 & 6.77 & & -0.40 & & -5.96 & \\
\hline 11.07 .2016 & 7.22 & 6.99 & & -0.23 & & -3.30 & \\
\hline 12.07 .2016 & 7.22 & 6.59 & & -0.63 & & -9.59 & \\
\hline 13.07 .2016 & 7.22 & 6.90 & & -0.32 & & -4.61 & \\
\hline 14.07 .2016 & 7.21 & 6.73 & & -0.48 & & -7.12 & \\
\hline
\end{tabular}

Similarly, the solar energy was calculated for 4:00-20:00 interval and the results are presented in table 5 along with associated errors. The results show mainly negative absolute errors but also some positive ones. The negative absolute errors obtained both in 08:00-16:00 and 04:00-20:00 intervals indicate that the simulation model overestimated the direct solar irradiance over the entire day. The four days with negative absolute errors only in 08:0016:00 interval, corresponds to underestimations in the morning/evening periods and overestimations in the central part of the day. The fact that the mean absolute error in 04:0020:00 interval $\quad\left(-0.61 \mathrm{kWh} / \mathrm{m}^{2}\right)$ is not significantly higher than the one obtained in the 08:00-16:00 interval $\left(-0.53 \mathrm{kWh} / \mathrm{m}^{2}\right)$ indicates that the deviations are higher in the central interval of the day. 
Table 5. Simulated and experimental direct solar energy and associated errors (4:00-20:00)

\begin{tabular}{|c|c|c|c|c|c|c|c|}
\hline Day & $\begin{array}{c}\boldsymbol{E}_{\boldsymbol{B}} \\
{\left[\mathrm{KWh} / \mathrm{m}^{2}\right]}\end{array}$ & $\begin{array}{c}\boldsymbol{E}_{\boldsymbol{B}_{\text {exp }}} \\
{\left[\mathrm{KWh} / \mathrm{m}^{2}\right]}\end{array}$ & $\begin{array}{c}\boldsymbol{E}_{\boldsymbol{B}_{\text {exp } m}} \\
{\left[\mathrm{KWh} / \mathrm{m}^{2}\right]}\end{array}$ & $\begin{array}{c}\boldsymbol{\varepsilon}_{\boldsymbol{E}} \\
{\left[\mathrm{KWh} / \mathrm{m}^{2}\right]}\end{array}$ & $\begin{array}{c}\boldsymbol{\varepsilon}_{\boldsymbol{E} \boldsymbol{m}} \\
{\left[\mathrm{KWh} / \mathrm{m}^{2}\right]}\end{array}$ & $\begin{array}{l}\varepsilon_{r_{E}} \\
{[\%]}\end{array}$ & $\begin{array}{l}\varepsilon_{r_{E m}} \\
{[\%]}\end{array}$ \\
\hline 02.07 .2013 & 11.02 & 10.44 & \multirow{13}{*}{10.20} & -0.58 & \multirow{13}{*}{-0.61} & -5.55 & \multirow{13}{*}{-5.99} \\
\hline 22.07.2013 & 10.62 & 9.33 & & -1.29 & & -13.84 & \\
\hline 02.07 .2014 & 11.02 & 10.78 & & -0.24 & & -2.21 & \\
\hline 05.07 .2014 & 10.98 & 10.00 & & -0.98 & & -9.83 & \\
\hline 21.07 .2014 & 10.65 & 9.20 & & -1.45 & & -15.76 & \\
\hline 07.07 .2015 & 10.95 & 8.52 & & -2.43 & & -28.52 & \\
\hline 17.07.2015 & 10.75 & 10.90 & & 0.14 & & 1.33 & \\
\hline 22.07 .2015 & 10.62 & 10.81 & & 0.18 & & 1.70 & \\
\hline 25.07 .2015 & 10.54 & 9.82 & & -0.72 & & -7.33 & \\
\hline 11.07.2016 & 10.86 & 11.04 & & 0.18 & & 1.60 & \\
\hline 12.07.2016 & 10.84 & 10.47 & & -0.38 & & -3.59 & \\
\hline 13.07.2016 & 10.82 & 10.86 & & 0.04 & & 0.36 & \\
\hline 14.07 .2016 & 10.80 & 10.38 & & -0.42 & & -4.02 & \\
\hline
\end{tabular}

The mean experimental direct solar irradiance obtained for the monitoring period 2013-

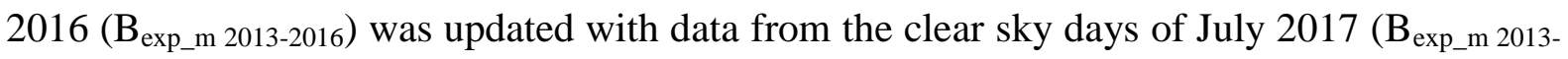
2017) and their variation are presented in Fig.5. The absolute errors between these are lower than $29.92 \mathrm{~W} / \mathrm{m}^{2}$ in 08:00-16:00 time interval. However, more investigations have to be done in terms of the number of years to be considered when trying to improve the accuracy of the simulation model due to the continuous climate change.

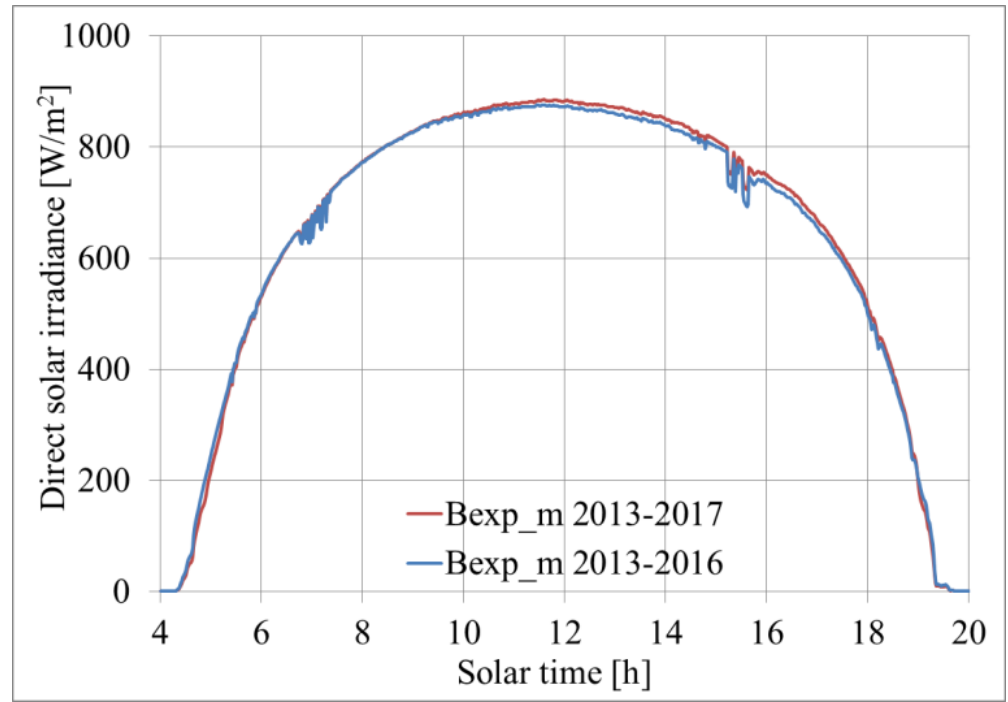

Fig.5 Mean experimental direct solar irradiance in July 2013-2016 and July 2013-2017 
If in the case of summer clear sky days, Meliss model overestimates the direct solar irradiance, in winter clear sky days the model generates underestimations. The experimental values obtained in $1^{\text {st }}$ of January 2016 (Fig. 6a) shows that in this case the model significantly underestimates the direct solar irradiance $\left(208.8 \mathrm{~W} / \mathrm{m}^{2}\right)$ and this occurs also in the central part of the day. Similar underestimation can be observed in Fig. $6 \mathrm{~b}$ for $19^{\text {th }}$ of November 2016.

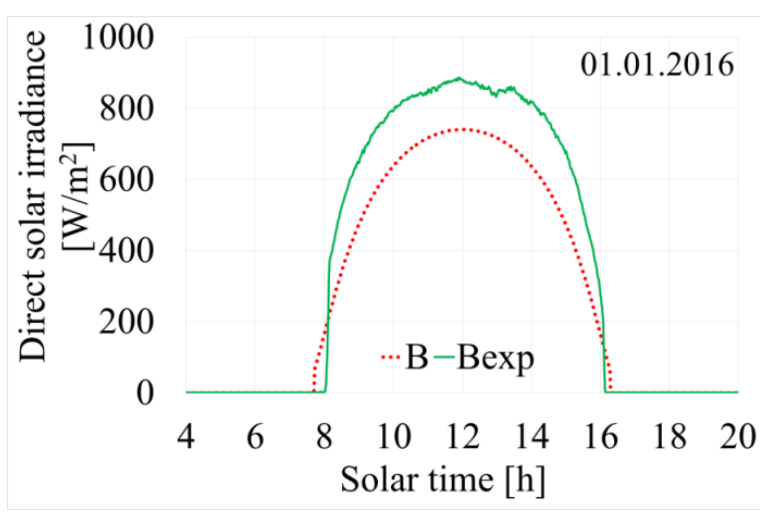

a)

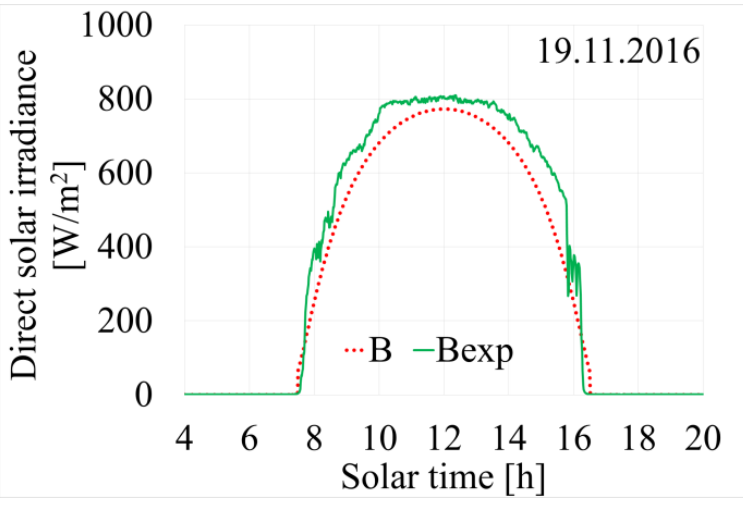

b)

Fig.6 Experimental and simulated direct solar irradiance in winter clear sky days

\section{Conclusions}

Direct solar irradiance measured in all clear sky days in July over the monitoring period 2013-2016 were analysed and compared with simulated values obtained with Meliss clear sky model. Excepting two out of the total of thirteen clear sky days, the model overestimates the direct solar irradiance with mean absolute error of $-140.86 \mathrm{~W} / \mathrm{m}^{2}$ corresponding to a mean relative error of $-20.35 \%$ in the time interval 08:00-16:00. In terms of direct solar energy received in this interval of time, the mean absolute error represents $-0.53 \mathrm{kWh} / \mathrm{m}^{2}$ and the mean relative error $-7.95 \%$. Considering the direct solar energy received during the whole daylight interval (04:00-20:00), the mean absolute error only increases to $-0.61 \mathrm{kWh} / \mathrm{m}^{2}$ showing the importance of an accurate estimation in the central part of the day (08:00-16:00).

Further research will be done to improve the accuracy of Meliss clear sky model especially in the central interval of the day (08:00-16:00) when the largest differences occur or to define a new model, not only for clear sky days, by analysing measured and simulated data on the entire year. Also, this study will be extended to morning and afternoon periods of time, when the results showed slight underestimations of the simulation model. Based on this research, a methodology which could be applied also for other locations will be proposed. 


\section{Acknowledgements}

This work was supported by a grant of the Romanian National Authority for Scientific Research and Innovation, CNCS/CCCDI-UEFISCDI, project number PN-III-P2-2.1-PED2016-0338, within PNCDI III.

\section{References}

[1] M. Meliss, Regenerative Energiequellen, Springer, Berlin (1997)

[2] A. Angstrom, Quarterly Journal of Royal Meteorological Society 50 (1924) 121-125

[3] J. A. Prescott, Transactions of the Royal Society of Australia 46 (1940) 114-118

[4] V. Badescu, Energy 24 (1999) 883-893

[5] J. Almorox, C. Hontoria and M. Benito, Applied Energy 88 (2011) 1703-1709

[6] A. H. Maghrabi, Energy Conversion and Management 50 (2009) 2754-2760

[7] P. Ineichen, Solar Energy 80 (2006) 468-478

[8] N. A. Engerer and F. P. Mills, Solar Energy 120 (2015) 9-24

[9] D. Isvoranu, V. Badescu, The Annals of the West University of Timisoara Physics Series LVII (2013) 24-33

[10] O. Mares, D. Vizman, M. Paulescu, The Annals of the West University of Timisoara Physics Series LVII (2013) 96-101

[11] V. Badescu, Theoretical and Applied Climatology 72 (2002) 127

[12] J. A. Duffie and W. A Beckman, Solar engineering of thermal processes, $4^{\text {th }}$ ed., John Wiley and Sons, Hoboken, New Jersey (2013)

[13] I. Visa, D. V. Diaconescu, M. V. Dinicu and B. G. Burduhos, Environmental Engineering and Management Journal 8-4 (2009) 843-847

[14] M. M. Vatasescu, M. D. Moldovan, B. G. Burduhos, Linkages for solar tracking, Publishing House of the Transilvania University of Brasov (2011)

[15] S. Kalogirou, Solar energy engineering processes and systems, Elsevier, Amsterdam (2014) 